Research Article

\title{
Simulation of Chloride Diffusion in Concrete Based on a New Mesoscopic Numerical Method
}

\author{
Ling Yao $\mathbb{D}$, Lixia Ren, Guoli Gong, and Jianqiang Zhang \\ Department of Resources and Environment, Shanxi Institute of Energy, No. 63, University Street, University Park, \\ Shanxi Province, Taiyuan, China \\ Correspondence should be addressed to Ling Yao; yaoling318@163.com
}

Received 1 February 2020; Revised 26 July 2020; Accepted 4 August 2020; Published 18 August 2020

Academic Editor: Daniele Baraldi

Copyright (c) 2020 Ling Yao et al. This is an open access article distributed under the Creative Commons Attribution License, which permits unrestricted use, distribution, and reproduction in any medium, provided the original work is properly cited.

Chloride diffusion-induced corrosion is a major factor that affects the durability of concrete structures. Thus, the study of chloride diffusion in concrete is important. In this study, a mesoscopic structure model is proposed and used to investigate chloride diffusion in concrete. The concrete is assumed to be a heterogeneous material composed of two phases of aggregate and mortar matrix. The aggregates are randomly distributed convex polygons. The chloride diffusion is assumed to occur only in the mortar matrix phase. The modified chloride diffusion coefficient in the mesoscale model is proposed. The effect of a single aggregate in chloride diffusion in concrete is analyzed. The present numerical model is validated on the basis of the experimental data. The influence of aggregate in the presented model, including aggregate random distribution form, aggregate content, and the validity of polygonal aggregate based on circle, is explored further. The simulation results indicate that the polygonal aggregate random distribution has a negligible influence on chloride diffusion in concrete, the polygonal aggregate content has a certain effect, and the presented mesoscale numerical model is an effect method for predicting the chloride diffusion in concrete.

\section{Introduction}

Chloride-induced reinforcement corrosion is a major cause of deterioration in reinforced concrete structures. This corrosion may result in serious damage to concrete structures and increased cost of repair and inspection $[1,2]$. Therefore, exploring the problem of chloride diffusion in concrete is important.

Considerable efforts have been made by using different methods to investigate various models to explain the diffusion behavior of chloride in heterogeneous concrete materials. Many researchers have explored the chloride diffusion in concrete by using experimental methods [3-11]. Considering the complex microstructure of concrete, its transport performance is affected by many interacting parameters. Many experiments should be conducted to identify the effects of different variables. However, it is difficult to implement because the variables affect one another inevitably. Moreover, the experiment is time consuming and laborious. All the aforementioned factors limit the experimental research.
In recent years, with the development of computers, an increasing number of mesoscopic methods have been used to simulate chlorine diffusion in concrete numerically. A lattice modeling for chloride ingress in concrete is adopted in [12]. Zeng [13] developed a two-phase structure model and simulated the chloride diffusion in concrete via the finite element method. Caré and Hervé [14] developed an analytical model to the diffusion coefficient of chloride in mortar, in which the concrete was treated as a three-phase composite that consisted of a cement phase, an aggregates phase, and an interface transition zone (ITZ). Moon et al. [15] examined the effect of capillary pores on chloride diffusion in concrete based on mercury intrusion porosimetry technique. Abyaneh et al. [16] investigated capillary absorption in concrete by treating concrete as a heterogeneous composite discretised into a cubic lattice. Du et al. [17] simulated a mesoscale three-phase model for chloride diffusion in concrete using the commercial software ABAQUS. Liu et al. [18] adopted a model based on a combined series and parallel multiphase transport to predict the chloride 
diffusion in concrete. Abyaneh et al. [19] used a three-dimensional model to simulate the effect of microcracks on the diffusivity of concrete. Mao et al. [20] analyzed electrochemical rehabilitation for ASR, and chloride affected concrete through a detailed multiphase modeling.

In the mesoscopic model, chloride diffusion in concrete is assumed to obey Fick's law without other heterogeneity on the influence of diffusion. The mesoscale mechanics of concrete has been discussed in recent decades with the development of multiscale mechanical theories. Roelfstra et al. [21] first introduced mesoscale model to study the performance of concrete mechanics. On the mesoscopic scale, concrete can be divided into a two-phase composite that consists of regular/irregular aggregates and mortar matrix [22-24] or is composed of aggregate, mortar matrix, and ITZ [20]. A comprehensive multiscale model is proposed to predict the diffusivity of concrete considering the effect of ITZ; the thickness of ITZ was assumed to be constant [25]. Notably, most of the existing modeling work assumes that the shape of an aggregate particle is circular or spherical. This rough simplification may cause inaccuracy in the simulation results [26]. More recently, the mesostructure of concrete with several aggregate shapes has been established to explore the effect of aggregate shape on the durability properties of concrete. A series of mesoscale numerical models with elliptical-, triangular-, and rectangular-type aggregate shapes are developed to examine the effects of aggregates on ionic migration [26] and the effect of elliptical aggregate was discussed on the basis of the mesoscopic model in [27, 28]. However, the aggregate was not circular, elliptical, triangular, or rectangular. In fact, the effect of aggregate shape cannot be ignored. Thus, a more realistic aggregate shape is required so that the effect of aggregate can be investigated accurately.

Notably, the mesoscopic model includes the two-phase aggregate and mortar matrix in concrete regardless of the kind of mesoscale models. ITZ is a thin layer between the aggregate and mortar matrix. Many researchers have investigated the microstructures of ITZ in concrete by using various methods. Determining the diffusivity of ITZ through experiments is complicated and difficult. Thus, this factor is usually neglected when calculating the uniform thickness. The ITZ thickness is usually 20, 40, and $50 \mu \mathrm{m}$ [29]; the value of ITZ thickness is $20 \mu \mathrm{m}$ in [30], it does not exactly coincide with the real thickness of ITZ; for example, it is between 30 and $80 \mu \mathrm{m}$ [31] and the thickness of ITZ is $100 \mu \mathrm{m}$ in [32]. So far, no uniform standard for ITZ layer thickness is available. Generally, the real thickness of ITZ is of micron dimension. Thus, simulating the chloride diffusivity in concrete is difficult because of the limitation in FEM [33-36]. Mesh is required in FEM method because it increases the calculation time significantly given that the number of elements is huge when the grid is small $[12,19]$. At the same time, the calculated thickness of the interfacial layer of all particles of different sizes is usually taken as a uniform thickness in its simulation for calculation limitation, and this thickness is expanded to $500 \mu \mathrm{m}$ and $1000 \mu \mathrm{m}$ or even higher multiples of the measured thickness so that the accuracy of simulation results is reduced $[17,33]$. In general, adopting the real ITZ thickness in the FEM simulated method to study the chloride diffusivity behavior in concrete is difficult because of the limitation of the computation.

The diffusion coefficient of ITZ $\left(D_{I T Z}\right)$ is difficult to measure. $D_{I T Z}$ value varies in many simulation methods. $D_{I T Z} / D_{C P}$ is $2.5 \sim 7$, which is the diffusion coefficient of cement mortar phase in [12], $D_{I T Z} / D_{C P}$ is 3 in [32], $D_{I T Z} / D_{C P}$ is 5 10 in [37-39], $D_{I T Z} / D_{C P}$ is $2 \sim 10$ in $[14,28]$, $D_{I T Z} / D_{C P}=16.2$ and $D_{I T Z} / D_{C P}=1.6 \sim 1.3$ [36]. $D_{I T Z} / D_{C P}$ is different in various relevant literatures; thus, a value differential is observed among the different references of $D_{I T Z}$.

Although numerical simulations have made some progress on chloride diffusion, relevant research, such as the influence of particle shape, is still incomplete. Thus, further work needs to be conducted. The present study focuses on the influences of mesostructure parameters on chloride diffusivity in concrete, including aggregate distribution, shape, and content.

Taking all these into account, to reveal the particulars of chloride diffusion in a heterostructural concrete, a simple two-phased structure model was constructed and used in this present article. The aggregate shape is a convex polygonal based on a circle. Therefore, the aggregate shape is much closer to the actual situation. The influences of aggregate distribution and content are discussed.

In this article, the chloride diffusion in concrete on mesoscopic scale is discussed. Section 2 describes the mesoscale model of concrete briefly. Section 3 shows the calibration of chloride diffusion coefficient on the basis of the new mesoscopic model. Section 4 examines the effect of single aggregate, different aggregate volume fractions, and aggregate contents on the chloride diffusion in concrete based on the simulation, where the present simulation result is compared with the experimental data in the literature [40]. Section 5 discusses the effect of aggregate (e.g., aggregate random distribution pattern, aggregate content, and polygonal aggregate) on chloride diffusion, followed by the conclusion section.

\section{Mesoscale Model of Concrete}

In the present work, the mesoscale concrete material constituents are the mortar matrix and aggregates. The mortar matrix is assumed to be homogeneous, no cracks are considered, and it is strongly dependent on the type of cement, number of pores, water-to-cement ratio, and other additives present used. Random spatial distribution and the popular take-place method $[34,41]$ are used to generate the coarse aggregate particles. The fine ones and other components (e.g., voids and cracks) were assumed to be mixed up with the cement paste when establishing the matrix phase.

The distribution of aggregate with different sizes used in the concrete specimen was determined by using a sieve analysis for a given aggregate volume fraction. The aggregate fraction refers to the volume fraction of coarse aggregate in unit volume concrete, and it is approximately 30\%-70\% in concrete [42]. Walraven et al. [43] converted the Fuller curve into the probability of any diameter aggregates in $2 \mathrm{D}$ as follows: 


$$
P_{c}\left(D<D_{0}\right)=P_{k}\left[1.065\left(\frac{D_{0}}{D_{\max }}\right)^{0.5}-0.053\left(\frac{D_{0}}{D_{\max }}\right)^{4}-0.012\left(\frac{D_{0}}{D_{\max }}\right)^{6}-0.045\left(\frac{D_{0}}{D_{\max }}\right)^{8}+0.0025\left(\frac{D_{0}}{D_{\max }}\right)^{10}\right]
$$

where $D_{0}$ is the diameter of sieve pore and $P_{k}$ is the percentage of aggregate volume.

We can calculate the percentage of different diameter aggregate volume fractions according to equation (1). Concrete may contain large aggregates, up to $32 \mathrm{~mm}$, when the material is used in conventional structures. However, for special applications, such as dams, aggregates larger than $150 \mathrm{~mm}$ are seldom applied. The distribution of the aggregate with different sizes was determined by using a sieve analysis for a given aggregate volume fraction, and three equivalent aggregate sizes (i.e., 6,12 , and $18 \mathrm{~mm}$ ) are used in the present study. The aggregate particles in real concrete are not perfect, and the coarse aggregate's shape varies; that is, it can be not only a sheet but also acicular. Coarse aggregate refers to the skeleton of concrete, and its shape, volume ration, gradation, and other problems have an important impact on the macroscopic performance of concrete. Therefore, establishing a reasonable coarse aggregate model that can reflect the real situation is the key to furthering the numerical simulation of concrete. Here, the polygonal aggregates are adopted. The generation of polygonal aggregate is nearly similar to that in circular aggregate, except that it only generates to random inscribed polygon in circle. Figure 1 depicts the mesoscale model of concrete adopted in the present work. The cyan areas and yellow zones correspond to the aggregate phase and mortar matrix phase, respectively. The aggregates' volume fraction is $50 \%$ in Figure 1 . The initial condition chloride concentration in concrete is zero in Figure 1. The chloride diffusion from the left boundary condition is $C_{s}$ in Figure 1(a) and the boundary condition is $C_{s}$ as shown in Figure 1(b). Considering that the aggregates within the cement paste usually have very poor diffusivity, the chloride diffusion is assumed to take place only in the mortar matrix phase $[19,20,27]$. In other words, considering the aggregate is relatively impermeable, assuming that the chloride diffusion coefficient in aggregate is zero is reasonable [44].

\section{Calibration of the Chloride Diffusion Coefficient in Mesoscale Model in Concrete}

The most commonly used equation for chloride diffusion in concrete is Fick's law. The chloride diffusion coefficient in aggregate is zero. Thus, the chloride diffusion in the mesoscale model of concrete is similar to the diffusion in porous material. When applying Fick's law to a porous material, such as concrete, the equation can be expressed as follows:

$$
\frac{\partial c}{\partial t}=\nabla \cdot\left(D_{\text {eff }} \nabla c\right)
$$

where $D_{\text {eff }}$ is an effective diffusion coefficient in concrete. $D_{\text {eff }}$, which is theoretically analogous to a useful treatment based on the mean field theory to calculate the effective diffusion coefficient for a two-phased structure by the following formula, is proposed by Zeng [13]:

$$
D_{\text {eff }}=D_{c p} \frac{D_{a}+k_{a} D_{c p}+k_{a} f_{a}\left(D_{a}-D_{c p}\right)}{D_{a}+k_{a} D_{c p}-f_{a}\left(D_{a}-D_{c p}\right)},
$$

where $D_{a}$ and $D_{c p}$ are the diffusion coefficients in the aggregate and the matrix phases, respectively; $f_{a}$ is the aggregate's volume fraction; and $k_{a}$ is the shape factor of the used aggregates. When the aggregate is spherically shaped and $D_{a}<D_{c p}$, as in the usual case, $k_{a}=2$ and $D_{a}=0$, according to equation (3); hence,

$$
D_{\text {eff }}=D_{c p} \frac{2\left(1-f_{a}\right)}{2+f_{a}} .
$$

In the method, the aggregate is assumed to have a spherical shape. In the study, the aggregate is assumed to be polygonal, and the calibration of the chloride diffusion is proposed. $V_{p}$ is the coarse aggregate area, $V_{B}$ is the area of the polygon inscribed circle, and $\alpha$ is the roundness of the coarse aggregate particles:

$$
\alpha=\frac{V_{p}}{V_{B}},
$$

where $\alpha$ is a number between zero and one. When $\alpha$ is greater, the aggregate shape is close to a spherical shape. The closer the particle shape is, the closer it is to needle flake (Figure 2).

The adopted number of polygon edges is 5 to 20 in the study. Due to the random inscribed polygons in a circle, we will use the concept of average roundness of the coarse aggregate particles as follows:

$$
\bar{\alpha}=\frac{\alpha_{5}+\alpha_{20}}{2},
$$

where $\alpha_{n}$ is roundness of $n$ side random inscribed polygon.

The permeability of ordinary aggregate is usually assumed to be zero in the process of diffusion. Chloride cannot diffuse through the aggregates, which is bound to bypass the aggregate particles to make the diffusion path extension. The effect of aggregate shape on chloride diffusion coefficient is different and similar to [13], and the calibration of chloride diffusion coefficient in this study is expressed as

$$
D_{\text {eff }}=\bar{\alpha} D_{c p} \frac{2\left(1-f_{a}\right)}{2+f_{a}} .
$$

\section{Results and Discussion}

Partial differential equation (2) can be solved using finite element methods. This study used the COMSOL Multiphysics package as the simulation platform. This software contains specific modules for diffusion and absorption/reaction in multiple dimensions. 


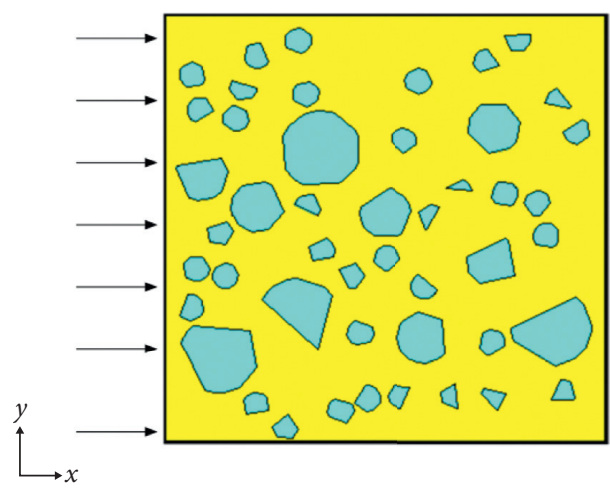

(a)

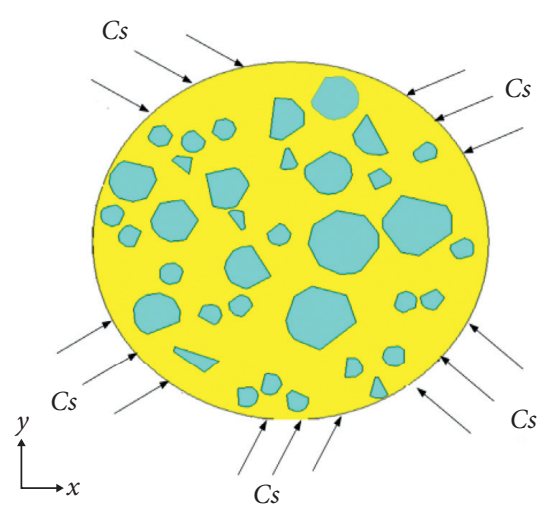

(b)

Figure 1: The mesoscale model of concrete.

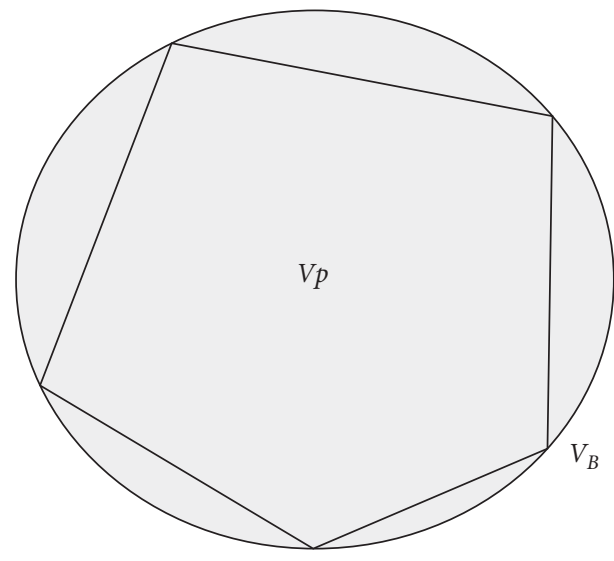

FIgURE 2: Roundness of aggregate diagram.

4.1. The Effect of Single Aggregate in Chloride Diffusion in Concrete. For example, when the side length is $0.5 \mathrm{~m}$ square concrete specimen, it is assumed that the left border of the critical concentration $C_{s}$ is $2 \%$, the rest of the sides are sealed, and $D_{\text {eff }}=4 \times 10^{-3} \mathrm{~m}^{2} /$ a. Generate a circle and a polygonal aggregate whose areas are $40 \%$ of the concrete's area, while generate a smaller circle and a polygonal aggregate, whose areas are $20 \%$ of the total area as in Figure 3. When the exposed time is 5 years, the distribution of chloride concentration in concrete is as shown in Figure 3. It is seen that the effect of different sizes and shape aggregates is discriminating. The width of the diffusion path shrinks when the front of the diffusion meets the aggregate. The width of the diffusion path increases, and the rate of diffusion slows down when the front of the diffusion meets the center of the aggregate.

4.2. Simulation and Analysis of the Experiment. The chloride diffusion in concrete was simulated based on the previous methods. Experimental data was from Mangat and Molloy [40], Mix A, which was based on OPC with $w / c=0.4$, was selected, and $C_{s}=1.5 \%$, Vagg $=0.5$ were adopted. The other parameters used were the same as those in [40].
The mesostructure of concrete is shown in Figure 1(a). Figure 4 plots the chloride concentration exposed time $t=2.8$ years. $D_{\text {eff }}$ is calculated according to equation (7). It can be noted clearly from Figure 4 that there is still a slight error between the experimental value and the simulated value. It is the main reason that specific mesoscale experimental values are not given in the original literature so the relevant values used in the simulation are all obtained by the least square regression. But, overall, the mesoscale numerical result shows a good correlation with experiment data. Contour is not straight because of polygon particles, which can change the path of chloride diffusion (Figure 5). The present two-dimensional numerical method can predict the chloride diffusion in concrete.

\section{Effect of Aggregate in This Mesoscale Model}

In this section, some numerical cases are designed to examine the effect of aggregate distribution mode and shape (Table 1). The influence of the chloride binding capacity and the temperature variation on chloride penetration was not considered for this presented model. Chloride diffusion is treated as a constant in the following simulation. Similar to the work in $[17,35,36], D_{c p}$ is assumed to be a constant in this study.

5.1. Effect of Aggregate Random Distribution Pattern. In this mesoscale model, the polygonal aggregate is a random generation based on Monte Carlo. Thus, the distribution of aggregate particles is different each time. For case 1, the specimen is $0.1 \mathrm{~m} \times 0.1 \mathrm{~m}$, and $0.1 \mathrm{~m}$ diameter is selected, as shown in Figure 1. $D_{\text {eff }}$ is obtained according to equation (7). Two different random polygonal aggregates are selected. When exposed time $t=10$ years, the contour of chloride concentration is shown in Figure 6. The chloride concentration when the depth is $0.05 \mathrm{~mm}$ along the diffusion direction in $0.1 \mathrm{~m} \times 0.1 \mathrm{~m}$ concrete is $0.2255 \%$ and $0.2256 \%$, respectively. The contours of the chloride concentration at the same position are almost the same. That is, the distribution pattern of aggregate almost has no influence on the chloride diffusion in concrete. 


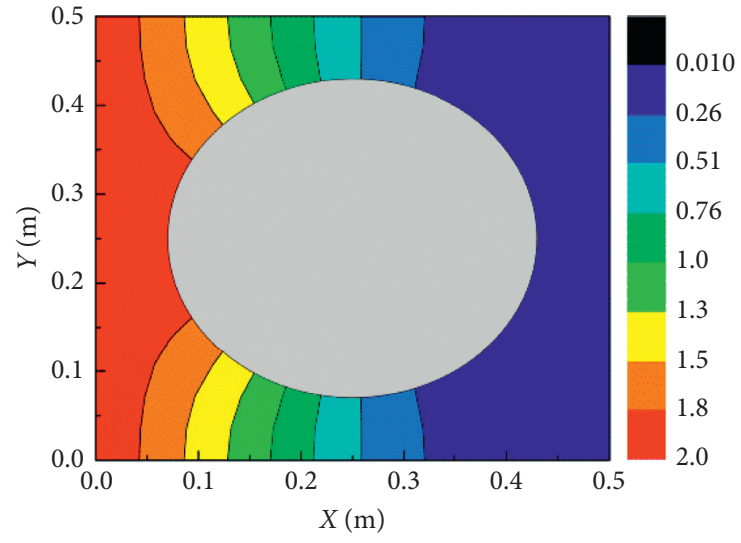

(a)

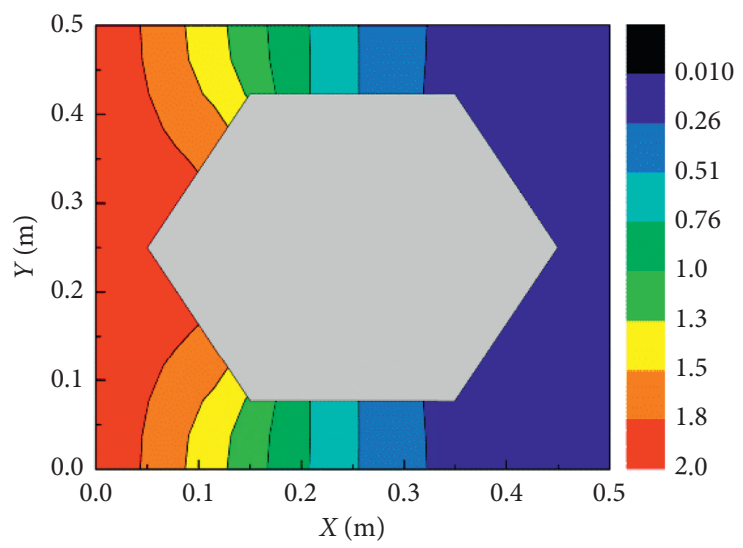

(c)

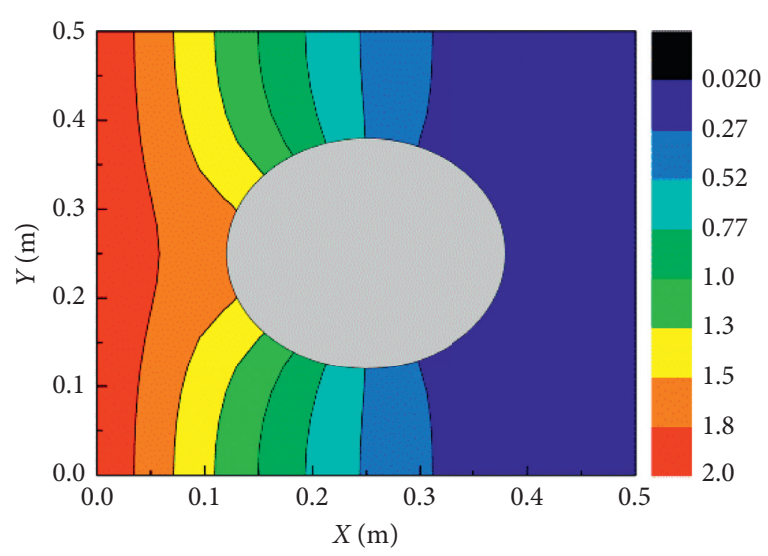

(b)

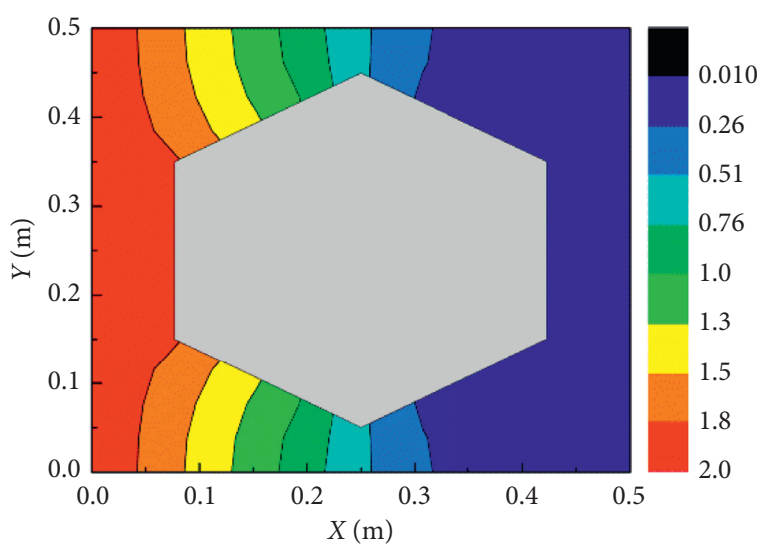

(d)

Figure 3: The distribution of chloride concentration in concrete ( $t=5$ years). (a) $40 \%$ circular aggregate. (b) $20 \%$ circular aggregate. (c) $40 \%$ polygonal aggregate. (d) 20\% polygonal aggregate.

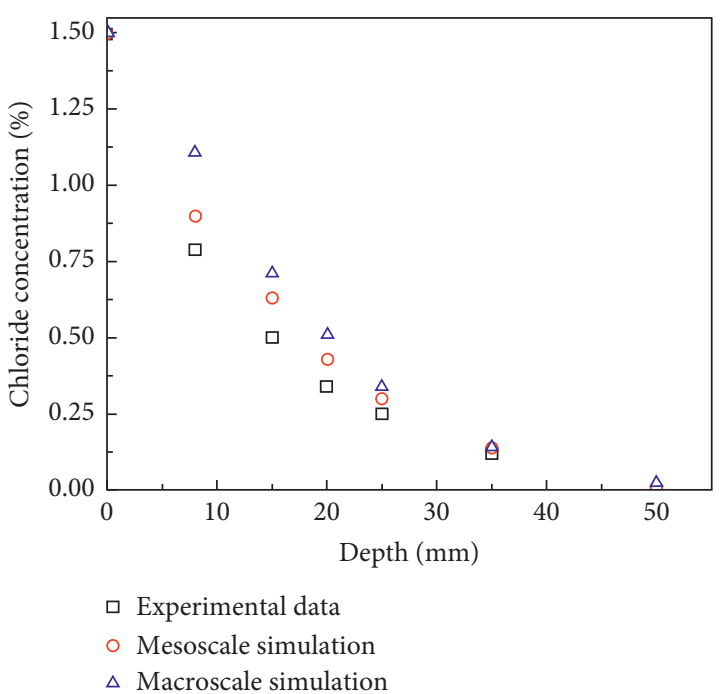

Figure 4: Comparison of the experimental data and simulated results.

5.2. Effect of Aggregate Content. For case 2, the effect of the volume fraction of aggregate was analyzed. The specimens are shown in Figure 1. The profiles of chloride concentration

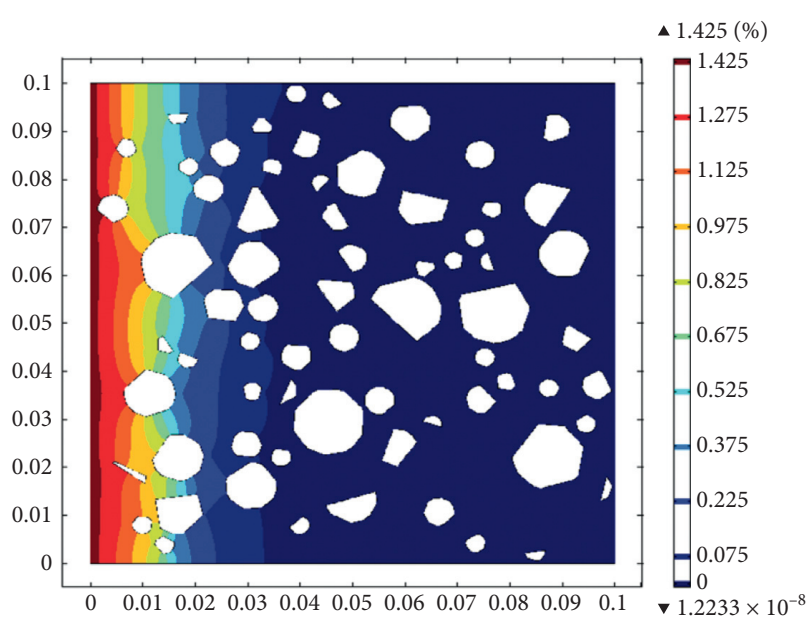

Figure 5: Distribution of chloride concentration ( $t=2.8$ years).

with different aggregate volume fractions and that of the cement paste when exposed time $t=15$ years and $t=5$ years, and $D_{\text {eff }}$ being the same, are described in Figure 7.

The chloride concentration is $0.03641 \%, 0.008154 \%$, and $0.0000405 \%$ at the right side; the depth is $0.5 \mathrm{~m}$ when $t$ is 15 years. Figure 7 shows that when the diffusion coefficient is 
TABle 1: Numerical design for aggregate analysis.

\begin{tabular}{lcccc}
\hline Test case & $C_{s}(\%)$ & $D_{c p}\left(\mathrm{~m}^{2} / \mathrm{s}\right)$ & Aggregate shape & Aggregate fraction $(\%)$ \\
\hline 1 & 1.5 & $5 \times 10^{-12}$ & Polygonal & 50 \\
2 & 1.5 & $5 \times 10^{-12}$ & Polygonal & $35,50,70$ \\
3 & 1.5 & $5 \times 10^{-12}$ & Circular, polygonal & 70 \\
\hline
\end{tabular}

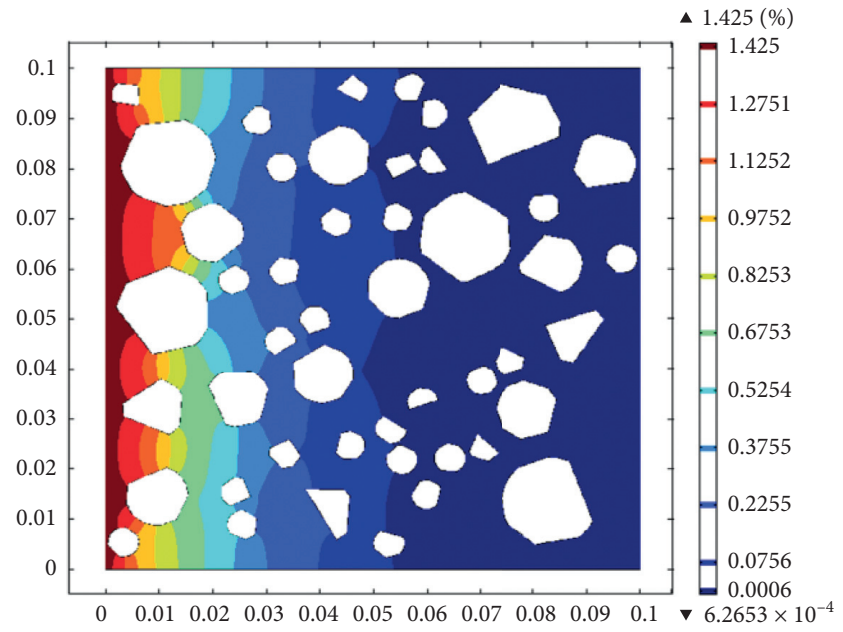

(a)

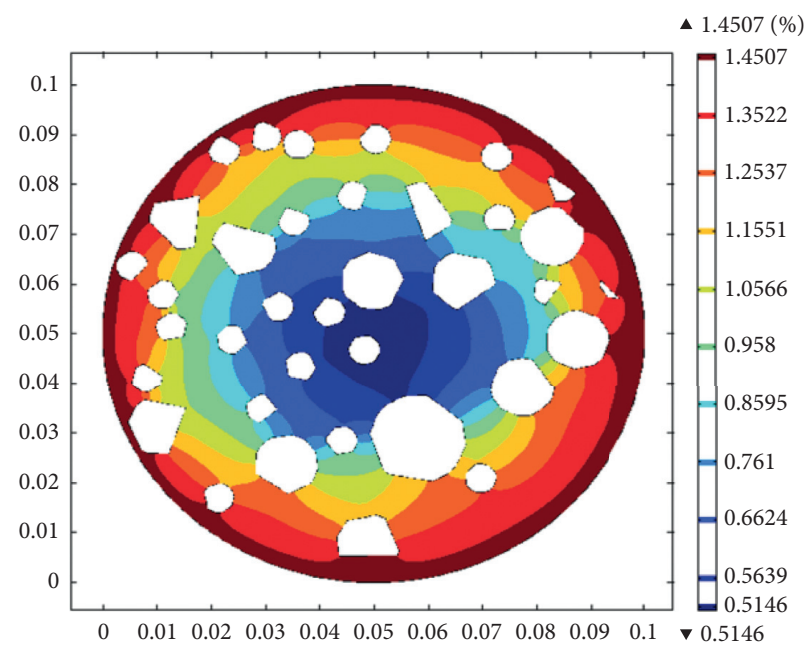

(c)

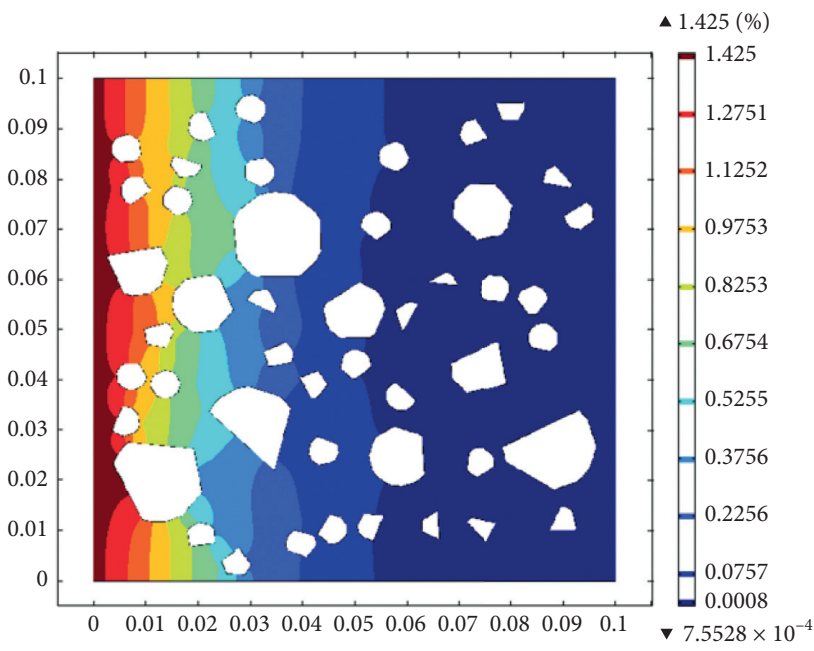

(b)

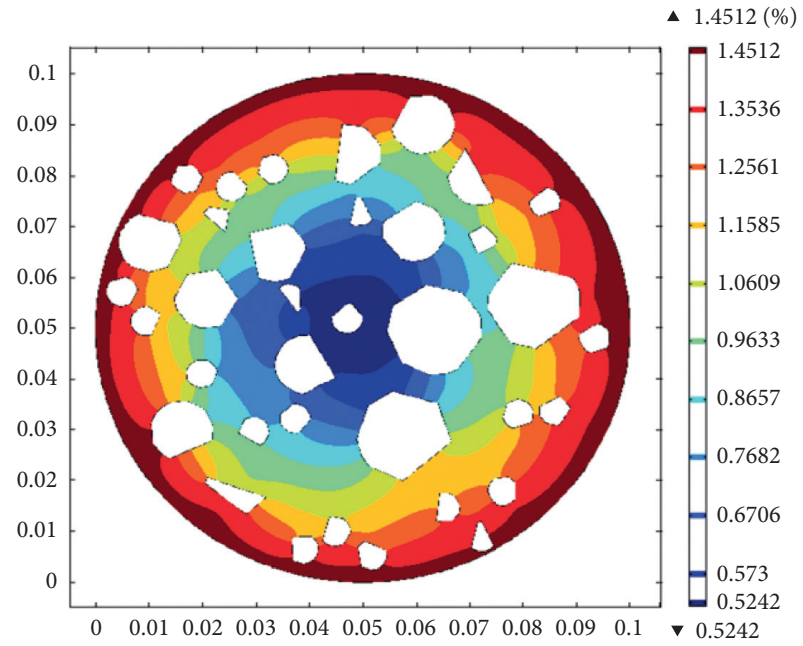

(d)

Figure 6: The distribution of chloride concentration at $t=10$ years.

the same, different aggregate volume fractions result in varying chloride concentrations in the same diffusion time. Along the diffusion direction, the chloride concentration decreases gradually, and the chloride concentration at the same depth decreases with the increase in aggregate volume fraction. In other words, with the increase in aggregate, the width of the diffusion path decreases, and the diffusion is impeded and weakened. When the aggregate content increases, the number of aggregate particles increases correspondingly in the numerical model. In the model, aggregate is considered impermeable. Thus, it is equivalent to a porous medium. When the number of aggregate particles increases, it is equivalent to an increase in porosity. The numerical simulation results show that the concentration of chlorine diffusion will also increase accordingly. This conclusion is consistent with the literature $[44,45]$.

5.3. Effect of Polygonal Aggregate. As for case 3, the effect of the present two-dimensional numerical method for polygonal aggregate can be proven again. When polygonal aggregate is adopted, $D_{\text {eff }}$ is solved by using equation (7). When the exposed time $t=30$ years, the distribution profile of chloride concentration of polygonal aggregate model is shown in Figure 8(a), and the distribution profile concentration of circular aggregate in the same condition is 


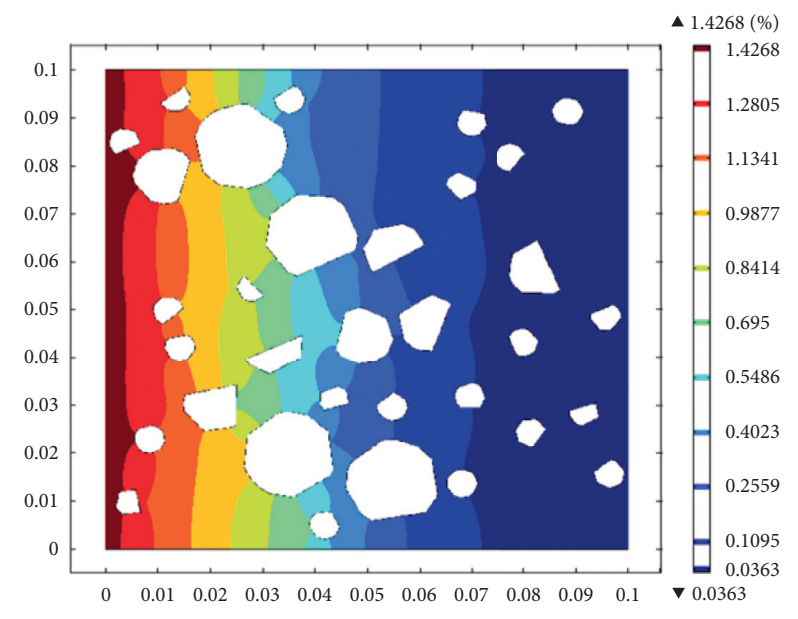

(a)

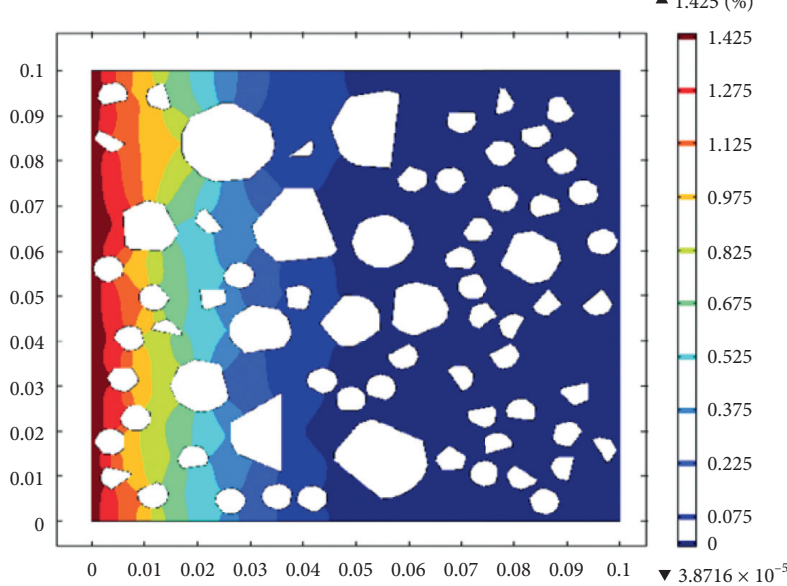

(c)

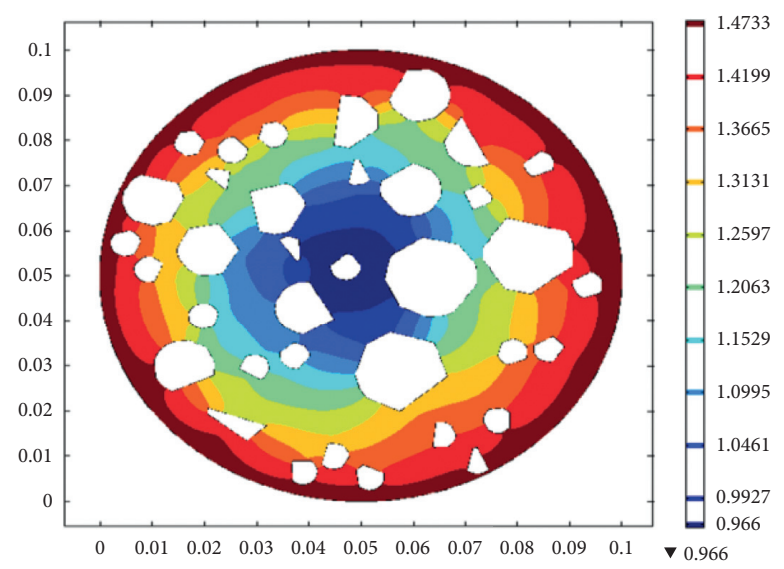

(e)

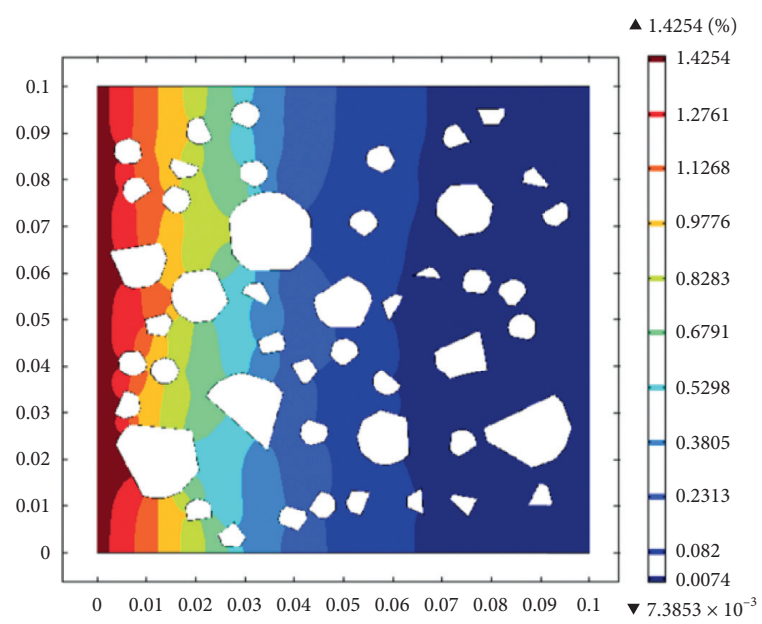

(b)

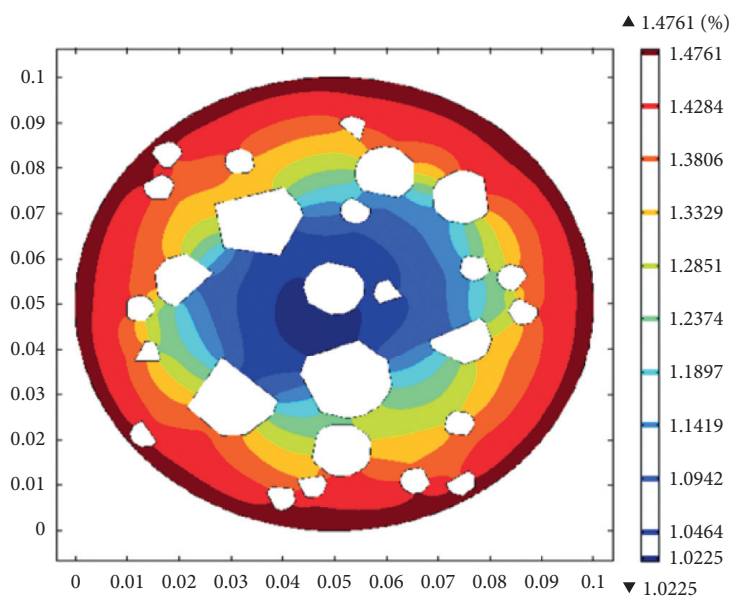

(d)

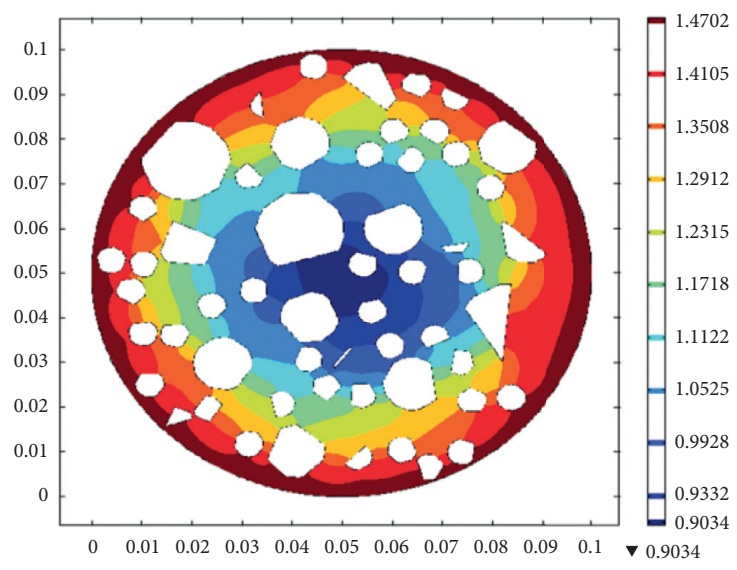

(f)

FIGURE 7: Distribution of chloride concentration at $t=5$ years and $t=15$ years. (a) $f_{a}=35 \%, t=15$ years. (b) $f_{a}=50 \%, t=15$ years. (c) $f_{a}=$ $75 \%, t=15$ years. (d) $f_{a}=35 \%, t=5$ years. (e) $f_{a}=50 \%, t=5$ years. (f) $f_{a}=75 \%, t=5$ years.

presented in Figure 8(b). For example, when the depth is $60 \mathrm{~mm}$ and exposed time $t=30$ years, the chloride concentration in Figure 8 (a) is $0.14 \%$. The chloride concentration in Figure 8 (b) under the same conditions is $0.19 \%$. These plots provide a clear view of chloride diffusion, and they may also manifest the effect of aggregate shape. The concentration in the polygonal aggregate model is smaller than that in the circular aggregate model in Figure 9. The reason is 


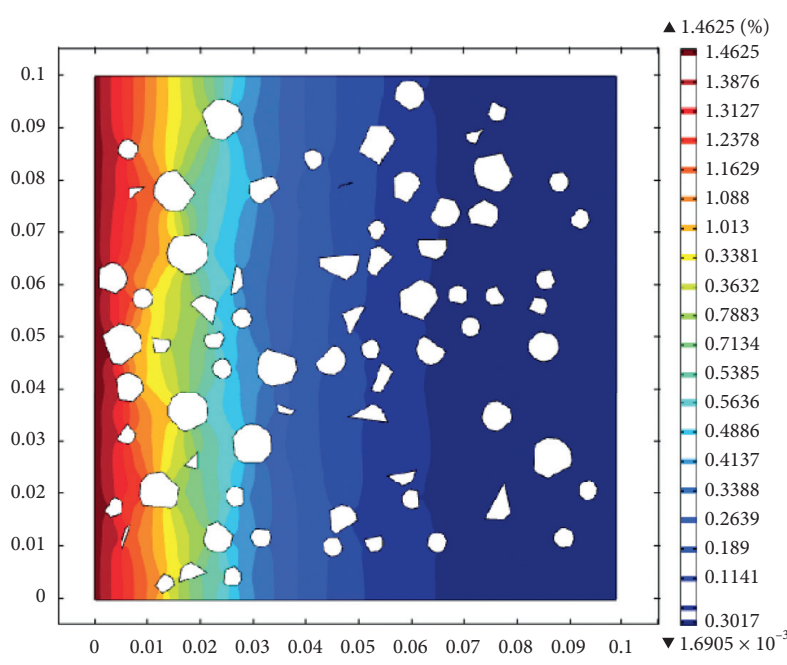

(a)

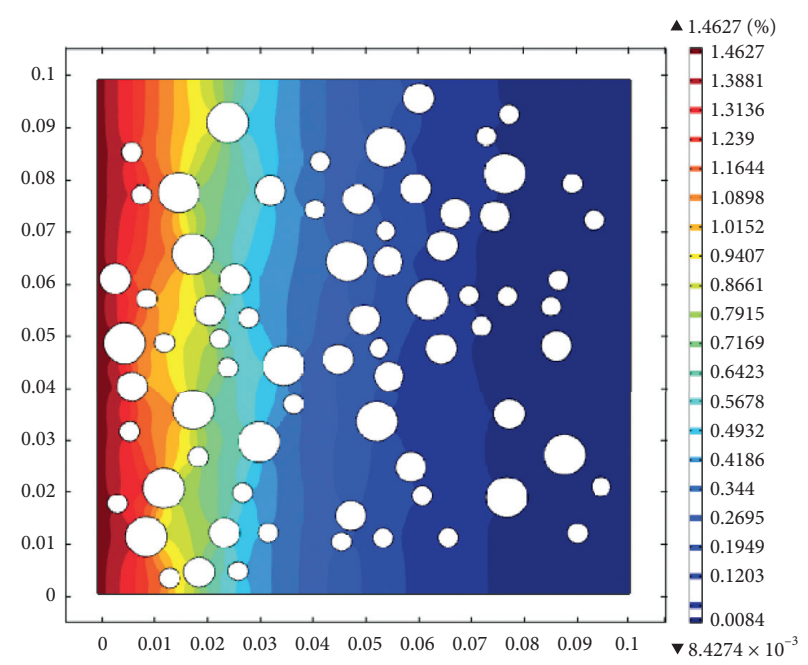

(b)

Figure 8: Distribution of chloride concentration in concrete. (a) Polygonal aggregate. (b) Circular aggregate.

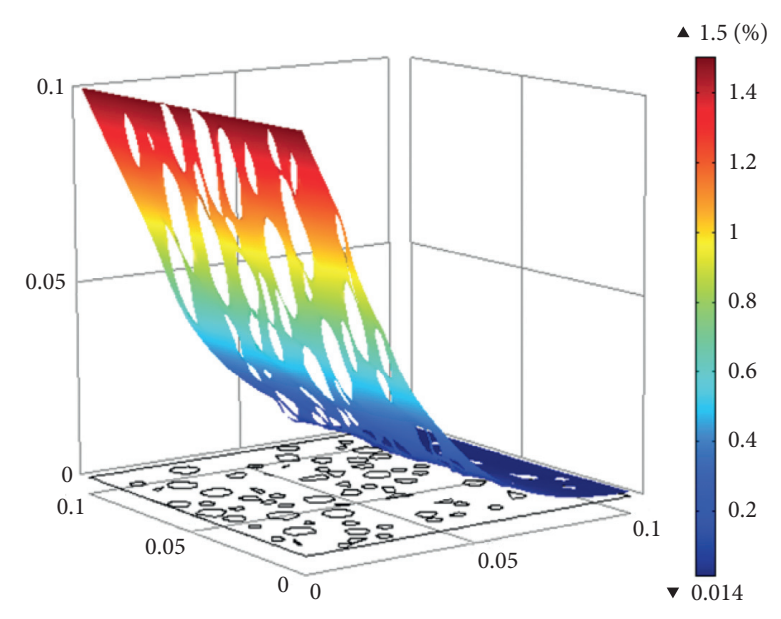

(a)

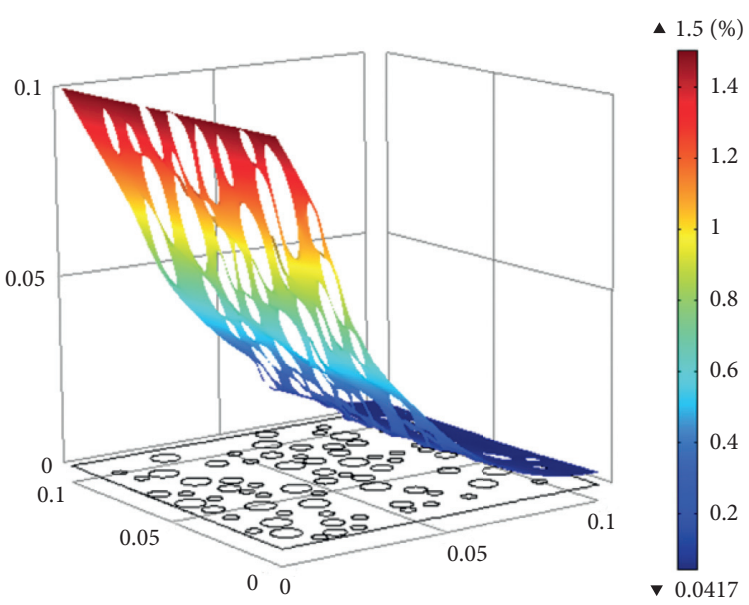

(b)

FIgURE 9: Distribution profile of chloride concentration from the mesoscopic model. (a) Polygonal aggregate. (b) Circular aggregate.

mainly because of the poor round base polygonal aggregate, which increases the diffusion path of tortuosity, thereby resulting in reduced diffusion velocity and low chloride concentration at the same depth. The conclusion is similar to literature [46], thereby further validating the mesoscopic model of polygonal aggregate for predicting the precision of chloride concentration.

\section{Conclusions}

In this work, a mesoscopic numerical model was presented on the basis of the polygonal aggregate, and the chloride diffusion in concrete was investigated. The proposed simulation method on mesoscopic level was verified by experimental values and simulated results. The method that adopted polygonal aggregate was realistic. The modified effective diffusion coefficient was presented, and the effect of polygonal aggregate was discussed. The following conclusions can be drawn on the basis of the obtained results:

(i) The mesoscale numerical model based on polygonal random aggregate that generates the tortuosity of diffusion path can provide the effective chloride diffusion coefficient, which includes the aggregate factor with a simple formula that can be expressed as $D_{\text {eff }}=\bar{\alpha} D_{c p} 2\left(1-f_{a}\right) / 2+f_{a}$.

(ii) The mesoscale numerical result based on polygonal random aggregate shows a good correlation with the experimental data. It further validated the mesoscopic model of the polygonal aggregate to predict the precision of chloride concentration.

(iii) The random distribution of polygonal aggregate has a negligible influence on chloride diffusion in concrete. 
(iv) An increment in the polygonal aggregate content increases the tortuosity of the chloride diffusion path and decreases the global chloride diffusion speed.

Finally, the presented model can be used successfully in simulating chloride penetration. The presence of polygonal coarse aggregates in concrete can be included in the model and provide more insights into the transport behavior. In all the analyses presented in this work, concrete was assumed to be fully saturated. Consequently, capillary suction and the effects of chloride binding were not considered. The next step can carry out relevant simulated calculation.

\section{Data Availability}

The data used to support the findings of this study were supplied by Ling Yao under license and so cannot be made freely available. Requests for access to these data should be made to the corresponding author.

\section{Conflicts of Interest}

The authors declare that there are no conflicts of interest regarding the publication of this paper.

\section{Acknowledgments}

The research was financially supported by the Institute Foundation ZB2018009, by the Fund for Shanxi "1331 Project” Key Subjects Construction.

\section{References}

[1] C. Sabine, "Influence of aggregates on chloride diffusion coefficient into mortar," Cement and Concrete Research, vol. 33, pp. 1021-1028, 2003.

[2] N. D. Stambaugh, T. L. Bergman, and W. V. Srubar, "Numerical service-life modeling of chloride-induced corrosion in recycled-aggregate concrete," Construction and Building Materials, vol. 161, pp. 236-245, 2018.

[3] D. P. Bentz, E. J. Garboczi, and E. S. Lagergren, "Multi-scale microstructural modeling of concrete diffusivity: identification of significant variables," Cement Concrete and Aggregates, vol. 20, pp. 129-139, 1998.

[4] K. Audenaert, Q. Yuan, and G. De Schutter, "On the time dependency of the chloride migration coefficient in concrete," Construction and Building Materials, vol. 24, no. 3, pp. 396402, 2010.

[5] P. Spiesz, M. M. Ballari, and H. J. H. Brouwers, "RCM: a new model accounting for the non-linear chloride binding isotherm and the non-equilibrium conditions between the free and bound-chloride concentrations," Construction and Building Materials, vol. 27, no. 1, pp. 293-304, 2012.

[6] H.-J. Chen, S.-S. Huang, C.-W. Tang, M. A. Malek, and L.-W. Ean, "Effect of curing environments on strength, porosity and chloride ingress resistance of blast furnace slag cement concretes: a construction site study," Construction and Building Materials, vol. 35, pp. 1063-1070, 2012.

[7] A. Petcherdchoo, "Time dependent models of apparent diffusion coefficient and surface chloride for chloride transport in fly ash concrete," Construction and Building Materials, vol. 38, pp. 497-507, 2013.
[8] S.-W. Pack, M.-S. Jung, H.-W. Song, S.-H. Kim, and K. Y. Ann, "Prediction of time dependent chloride transport in concrete structures exposed to a marine environment," Cement and Concrete Research, vol. 40, no. 2, pp. 302-312, 2010.

[9] L. Y. Li and C. L. Page, "Finite element modelling of chloride removal from concrete by an electrochemical method," Corrosion Science, vol. 42, no. 12, pp. 2145-2165, 2000.

[10] O. Truc, J. P. Ollivier, and M. Carcassès, "A new way for determining the chloride diffusion coefficient in concrete from steady state migration test," Cement and Concrete Research, vol. 30, no. 2, pp. 217-226, 2000.

[11] C. Fu, X. Jin, H. Ye, and N. Jin, “Theoretical and experimental investigation of loading effects on chloride diffusion in saturated concrete," Journal of Advanced Concrete Technology, vol. 13, no. 1, pp. 30-43, 2015.

[12] B. Šavija, M. Luković, and E. Schlangen, "Lattice modeling of rapid chloride migration in concrete," Cement and Concrete Research, vol. 61-62, pp. 49-63, 2014.

[13] Y. Zeng, "Modeling of chloride diffusion in hetero-structured concretes by finite element method," Cement and Concrete Composites, vol. 29, no. 7, pp. 559-565, 2007.

[14] S. Caré and E. Hervé, "Application of a n-phase model to the diffusion coefficient of chloride in mortar," Transport in Porous Media, vol. 56, pp. 119-135, 2004.

[15] H. Y. Moon, H. S. Kim, and D. S. Choi, "Relationship between average pore diameter and chloride diffusivity in various concretes," Construction and Building Materials, vol. 20, no. 9, pp. 725-732, 2006.

[16] S. Dehghanpoor Abyaneh, H. S. Wong, and N. R. Buenfeld, "Computational investigation of capillary absorption in concrete using a three-dimensional mesoscale approach," Computational Materials Science, vol. 87, pp. 54-64, 2014.

[17] X. Du, L. Jin, and G. Ma, "A meso-scale numerical method for the simulation of chloride diffusivity in concrete," Finite Elements in Analysis and Design, vol. 85, pp. 87-100, 2014.

[18] Q.-F. Liu, D. Easterbrook, L.-Y. Li, and D. Li, "Prediction of chloride diffusion coefficients using multi-phase models," Magazine of Concrete Research, vol. 69, no. 3, pp. 134-144, 2017.

[19] S. D. Abyaneh, H. S. Wong, and N. R. Buenfeld, "Simulating the effect of microcracks on the diffusivity and permeability of concrete using a three-dimensional model," Computational Materials Science, vol. 119, pp. 130-143, 2016.

[20] L.-X. Mao, Z. Hu, J. Xia et al., "Multi-phase modelling of electrochemical rehabilitation for ASR and chloride affected concrete composites," Composite Structures, vol. 207, pp. 176-189, 2019.

[21] P. E. Roelfstra, H. Sadouki, and F. H. Wittmann, "Le béton numérique," Materials and Structures, vol. 18, no. 5, pp. 327-335, 1985.

[22] Y. Liu, Y. Huang, W. Sun, H. Nair, D. S. Lane, and L. Wang, "Effect of coarse aggregate morphology on the mechanical properties of stone matrix asphalt," Construction and Building Materials, vol. 152, pp. 48-56, 2017.

[23] E. A. Bonifaz, J. Baus, and E. O. L. Lantsoght, "Modeling concrete material structure: a two-phase meso finite element model," Journal of Multiscale Modelling, vol. 8, pp. pp1-pp12, 2017.

[24] H. He, Z. Guo, P. Stroeven, M. Stroeven, and L. J. Sluys, "Characterization of the packing of aggregate in concrete by a discrete element approach," Materials Characterization, vol. 60, no. 10, pp. 1082-1087, 2009.

[25] A. U. Nilsen and P. J. Monteiro, "Concrete: a three phase material," Cement and Concrete Research, vol. 23, pp. 147-151, 1993. 
[26] Q.-F. Liu, G.-L. Feng, J. Xia, J. Yang, and L.-Y. Li, "Ionic transport features in concrete composites containing various shaped aggregates: a numerical study," Composite Structures, vol. 183 , pp. 371-380, 2018

[27] S. Dehghanpoor Abyaneh, H. S. Wong, and N. R. Buenfeld, "Modelling the diffusivity of mortar and concrete using a threedimensional mesostructure with several aggregate shapes," Computational Materials Science, vol. 78, pp. 63-73, 2013.

[28] J.-J. Zheng, X.-Z. Zhou, Y.-F. Wu, and X.-Y. Jin, "A numerical method for the chloride diffusivity in concrete with aggregate shape effect," Construction and Building Materials, vol. 31, pp. 151-156, 2012.

[29] C. C. Yang and J. K. Su, "Approximate migration coefficient of interfacial transition zone and the effect of aggregate content on the migration coefficient of mortar," Cement and Concrete Research, vol. 32, no. 10, pp. 1559-1565, 2002.

[30] B. H. Oh and S. Y. Jang, "Prediction of diffusivity of concrete based on simple analytic equations," Cement and Concrete Research, vol. 34, no. 3, pp. 463-480, 2004.

[31] A. Delagrave, J. P. Bigas, J. P. Ollivier, J. Marchand, and M. Pigeon, "Influence of the interfacial zone on the chloride diffusivity of mortars," Advanced Cement Based Materials, vol. 5, no. 3-4, pp. 86-92, 1997.

[32] Q.-F. Liu, D. Yang, J. Yang, and L.-Y. Li, "A three-phase, multi-component ionic transport model for simulation of chloride penetration in concrete," Engineering Structures, vol. 86, pp. 122-133, 2015.

[33] B. Šavija, J. Pacheco, and E. Schlangen, "Lattice modeling of chloride diffusion in sound and cracked concrete," Cement and Concrete Composites, vol. 42, pp. 30-40, 2013.

[34] P. Grassl and M. Jirásek, "Meso-scale approach to modelling the fracture process zone of concrete subjected to uniaxial tension," International Journal of Solids and Structures, vol. 47, no. 7-8, pp. 957-968, 2010.

[35] J. F. Unger and S. Eckardt, "Multiscale modeling of concrete," Archives of Computational Methods in Engineering, vol. 18, no. 3, pp. 341-393, 2011.

[36] S. Kamali-Bernard and F. Bernard, "Effect of tensile cracking on diffusivity of mortar: 3D numerical modelling," Computational Materials Science, vol. 47, no. 1, pp. 178-185, 2009.

[37] J. Xiao, L. Shen, J. Ying, and M. A. Bradford, "Five-phase composite sphere model for chloride diffusivity prediction of recycled aggregate concrete," Magazine of Concrete Research, vol. 65, pp. 573-588, 2013.

[38] J. J. Zheng and X. Z. Zhou, "Prediction of the chloride diffusion coefficient of concrete," Materials and Structures, vol. 40, no. 7, pp. 693-701, 2007.

[39] H. Byung, O. Hwan, and Y. Seung, "Prediction of diffusivity of concrete based on simple analytic equations," Cement and Concrete Research, vol. 34, no. 3, pp. 463-480, 2004.

[40] P. S. Mangat and B. T. Molloy, "Prediction of long term chloride concentration in concrete," Materials and Structures, vol. 27 , no. 6, pp. 338-346, 1994.

[41] P. Wriggers and S. O. Moftah, "Mesoscale models for concrete: homogenisation and damage behaviour," Finite Elements in Analysis and Design, vol. 42, no. 7, pp. 623-636, 2006.

[42] J. J. Zheng, C. Q. Li, and L. Y. Zhao, "Simulation of twodimensional aggregate distribution with wall effect," Journal of Materials in Civil Engineering, vol. 15, no. 5, pp. 506-510, 2003.

[43] J. Walraven and H. Reinhardt, "Theory and experiments on the mechanical behaviour of cracks in plain and reinforced concrete subjected to shear loading," Heron, vol. 26, no. 1, 1981.
[44] W.-Q. Jiang, X.-H. Shen, S. Hong, Z.-Y. Wu, and Q.-F. Liu, "Binding capacity and diffusivity of concrete subjected to freeze-thaw and chloride attack: a numerical study," Ocean Engineering, vol. 186, Article ID 106093, 2019.

[45] X.-H. Shen, W.-Q. Jiang, D. Hou, Z. Hu, J. Yang, and Q.-F. Liu, "Numerical study of carbonation and its effect on chloride binding in concrete," Cement and Concrete Composites, vol. 104, Article ID 103402, 2019.

[46] Q.-F. Liu, J. Yang, J. Xia, D. Easterbrook, L.-Y. Li, and X.-Y. Lu, "A numerical study on chloride migration in cracked concrete using multi-component ionic transport models," Computational Materials Science, vol. 99, pp. 396416, 2015. 